\title{
The Effect of Playing-based Exercises on Weight, Body Mass Index, and Fat Percentage of Overweight Children with Developmental Coordination Disorder
}

\begin{abstract}
Background and Objective: Body composition changes effects on physical, motor, and psychic aspects of people. The purpose of this study was to investigate the effect of playing-based exercises on weight, body mass index, and fat percentage of overweight children with developmental coordination disorder.

Materials and Methods:The research method is semi experimental, with pretest and post-test design. After checking health records, height and weight, and completing the questionnaire, from among the primary schools in district 15 of Tehran, 50 children, aged 8 to 10 , were selected through targeted sampling method and based on entry criteria in 2015 . After pre-test, they were randomly divided into two experimental groups $(n=30)$ and control group $(n=20)$. The experimental group participated in the protocol and received 3 sessions per week for 3 months. MABC-2 motor development test was used to measure the coordination of subjects and calipers and scales were used to combine the body. Data was analyzed using SPSS 21 and one-way covariance analysis at a significant level of 0.05 .

Results: Analysis of variables after 12 weeks of intervention indicated weight loss, fat percentage and body mass index in the experimental group and the intervention group received better scores compared to the control group and this difference was significant.

Conclusion: Performing physical activity in the form of a game is one of the effective ways of intervening in children. Therefore, with early intervention, we can have a positive effect on the growth process and overweight.

Keywords: Developmental coordination disorder, Fat percentage, Body mass index, Child

Paper Type: Research Article.
\end{abstract}

Citation (Vancouver): Shoja M, Kazem Vaez Mousavi M, Ghasemi A. The Effect of Playing-based Exercises on Weight, Body Mass Index, and Fat Percentage of Overweight Children with Developmental Coordination Disorder. Iran J Health Educ Health Promot. Autumn 2019;7(3):274-284. [Persian]

> Citation (APA): Shoja M., Kazem Vaez Mousavi M., Ghasemi A. (Autumn 2019). The Effect of Playing-based Exercises on Weight, Body Mass Index, and Fat Percentage of Overweight Children with Developmental Coordination Disorder. Iranian Journal of Health Education \& Health Promotion., 7(3),274-284. [Persian]
Maryam Shoja

Dept. of Physical Education, Faculty of Humanities, Science and Research Branch, Islamic Azad University, Tehran, Iran.

Seyed Mohammad Kazem Vaez

Mousavi

* Dept. of Physical Education, Faculty of Humanities, University of Imam Hossein, Tehran, Iran. (corresponding Author):

mohammadvaezmousavi@chmail.ir

Abdollah Ghasemi

Dept. of Physical Education, Faculty of Humanities, Science and Research Branch, Islamic Azad University, Tehran, Iran.

Received: 23 December 2018 Accepted: 29 May 2019

DOI: 10.30699/ijhehp.7.3.274 


\section{ثأثير تمرينات بازىمحور بر وزن، شاخص توده بدن و درصد جربعى كودكان}

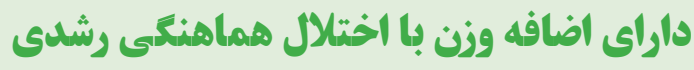

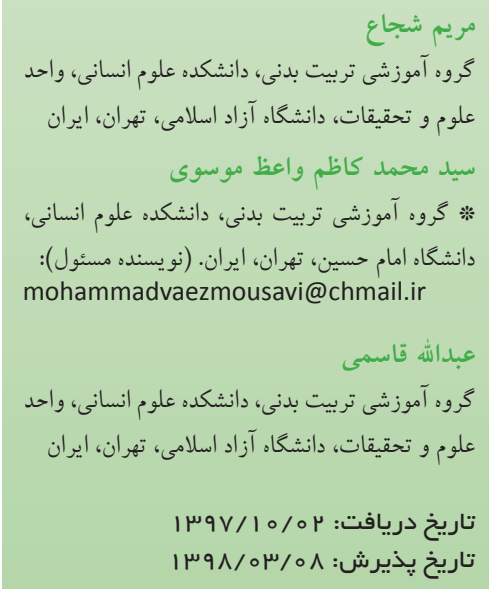

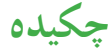

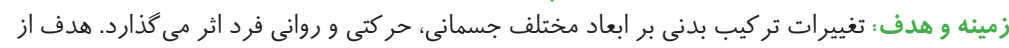

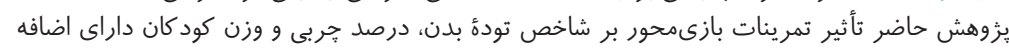
وزن با اختلال هماهنخى روأنير تمرينات بازى است.

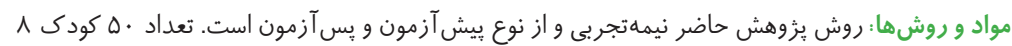

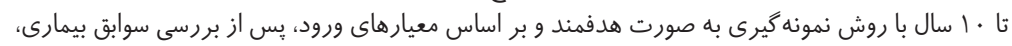

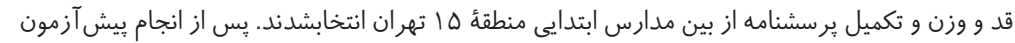

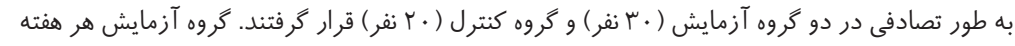

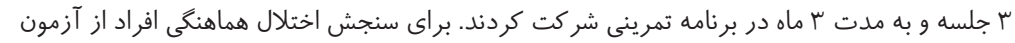

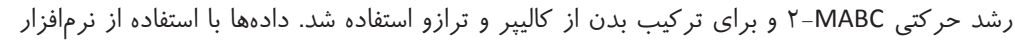

SPSS

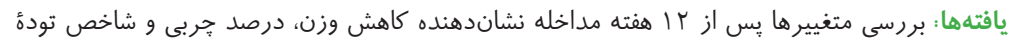

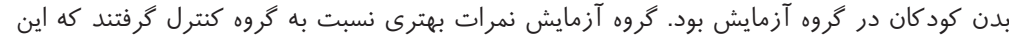
تفاوت معنادار بود.

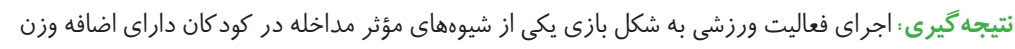

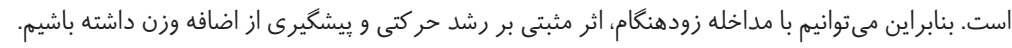

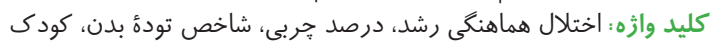
نوع مقاله : مطالعه يزوهشى. اخلال همانى

4 استناد (ونكوور) : شجاع م، كاظم واعظ موسوى م، قاسمى ع. ثأثير تمرينات بازىمحور بر وزن، شاخص

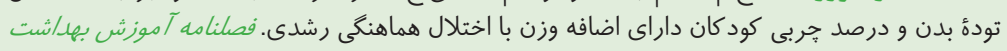

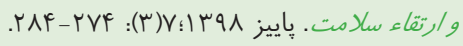

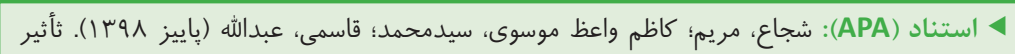

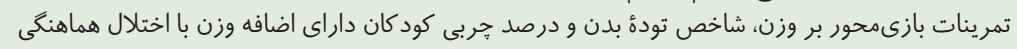

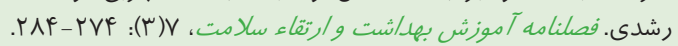


طور قابل ملاحظهاى شاخص توده بدنى بالاتر، محيط كمر بيشتر و

درصد جربى بالاترى نسبت به همتايان خود دارند (11). جاقى و اضافه وزن دو عاملى هستند كه با هم ارتباط دارند. ريسك ابتلا به اختلال هماهنكى رشدى در افراد جاق نسبت به افر افر اد

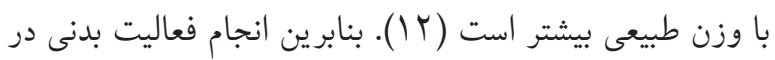

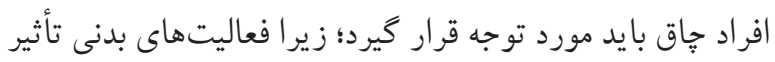

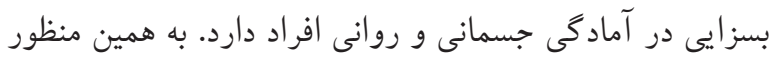

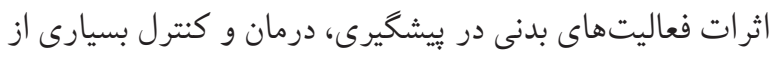

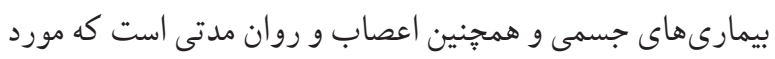
توجه متخصصان تربيت بدنى و علوم ورزشى قرار كرفته است (I (I).

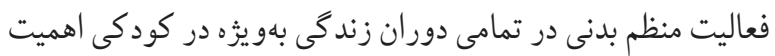

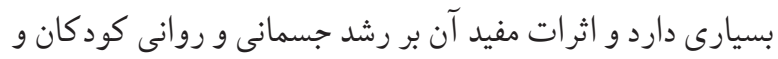

نوجوانان نبايد ناديده گرفته شود (If).

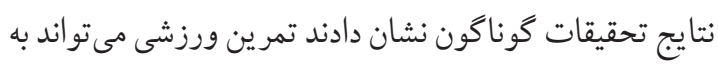
افزايش توده عضلانى و بهبود وضعيت تركيب بدنى افراد جاق كمك لهن كند (10) و موجب كاهش توده جربى از طريق افز ايش متابوليسم پايه

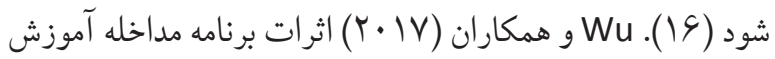
متقابل را بر تر كيب بدن، آمادگى قلبى تنفسى، تعادل و استقامت

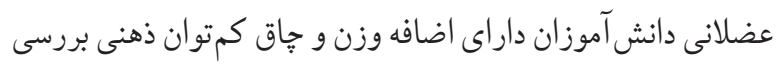

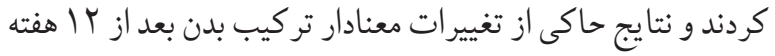

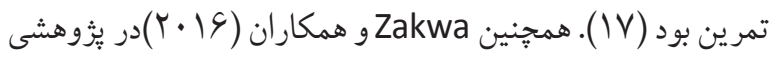

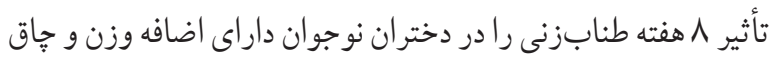

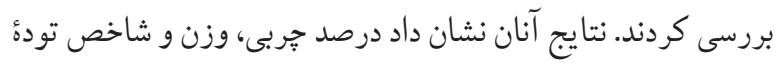

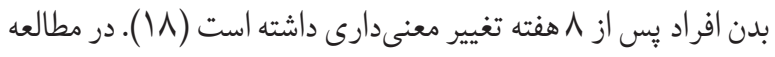
Dashti Khudaki

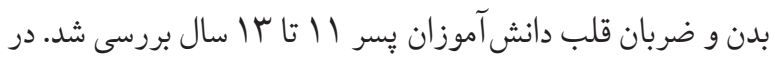
اين تحقيق تمرينات در نظر كرفتهشده بيشتر از نوع هوازى بودند

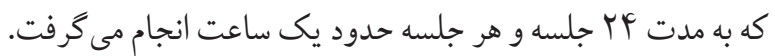

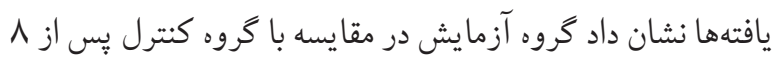

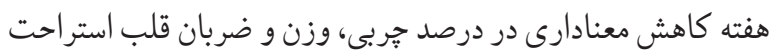

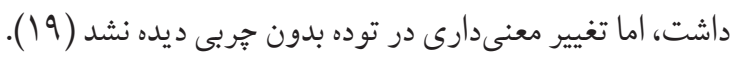

جاقى و اضافه وزن بزرگترين معضل سلامتى در دنياى صنعتى و مدرن محسوب مى شود. آمارها نشان مى دهد در سراسر جهان

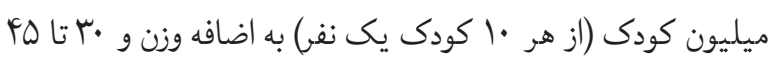
ميليون به جاقى مبتلا هستند (1). سازمان جهانى بهداشت اظهار

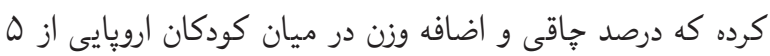

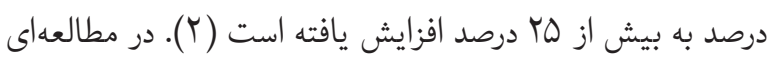

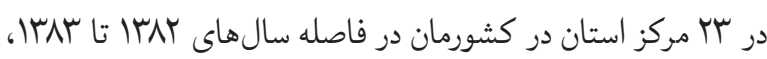

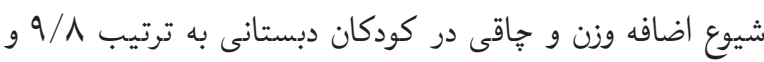

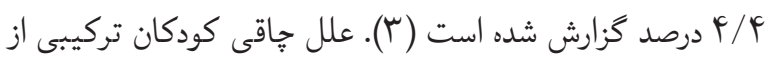

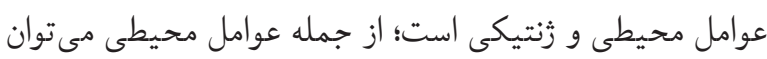

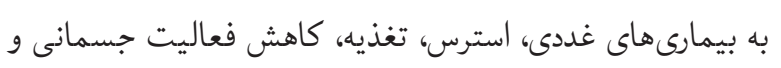

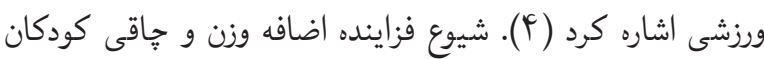
روندى جهانى است و سبب بروز ناراحتى هاى مرتبط با تندرستى، ورنى ورنى

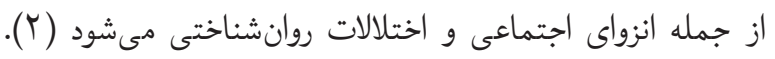

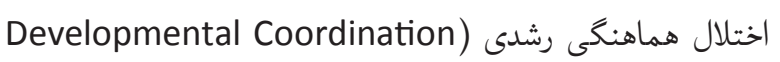
(Disorder فرد كمتر از سن تقويمى اوست، بدون اينكه بيمارى خاصى داشته

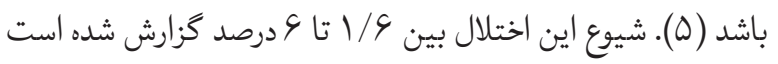

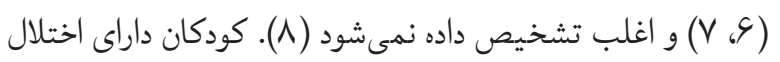
هماهنكى رشد عموماً در مهارتهاى درشت و ظريف تبحر كافى داد ندى

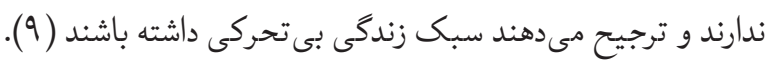

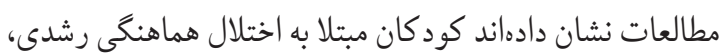

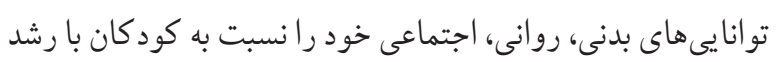

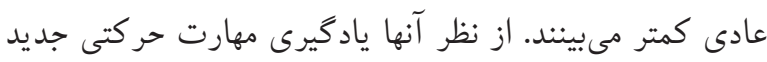

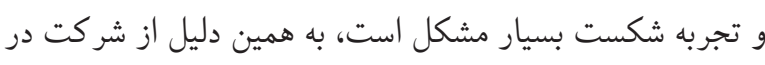

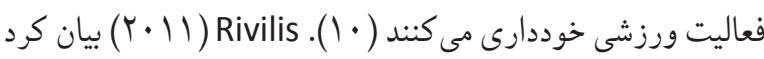

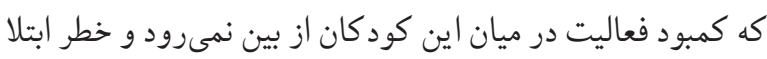

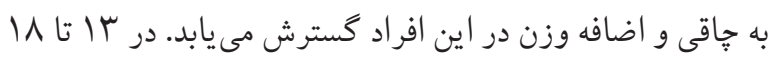

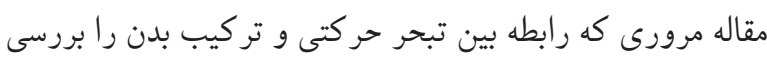

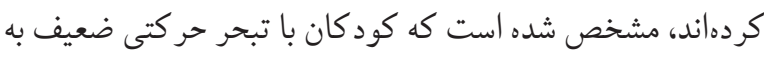


مو اد و روشها

يُّوهش حاضر از نوع نيمهتجربى با طرح بيش آزمون و يس آزمون

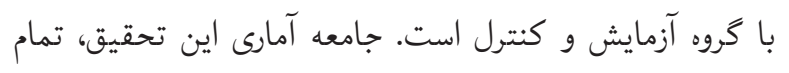

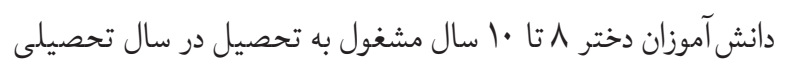

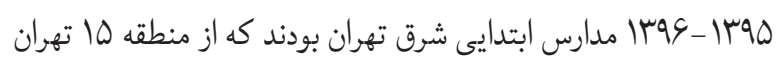

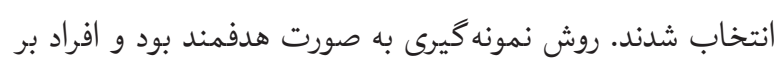
اساس معيارهاى ورود از بين پِرجمعيت ترين مدارس ابتدايى منطقه

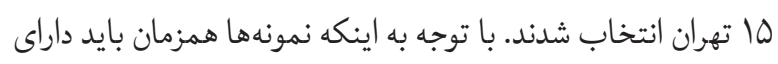

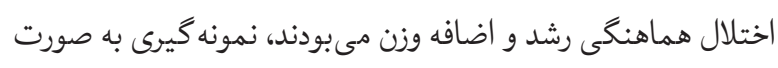

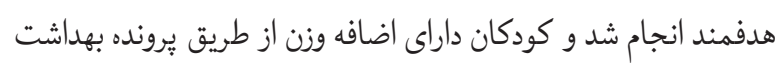
مدارس شناسايى شدند و به خانوادههاى آنها اطللاع داده شد كه جنانجه إنه مايل هستند در اين تحقيق شركت كنند به مديران مدارس اطللاع

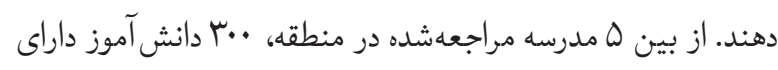

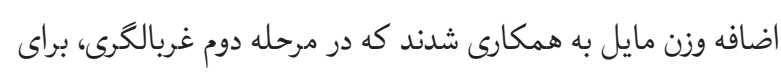
تشخيص اختلال هماهنكى، يرسشنامه ويلسون به افراد داده شد و

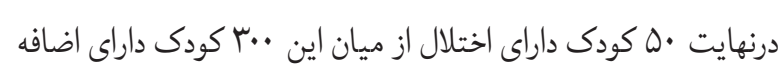
وزن براى ادامه تحقيق بركزيده شدند. افراد به صورت تصادفى ساده

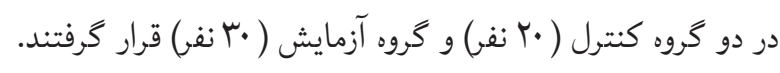

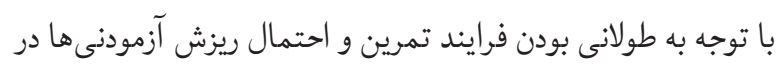

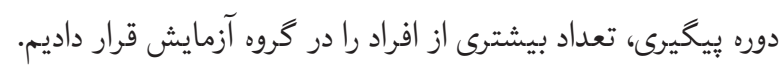

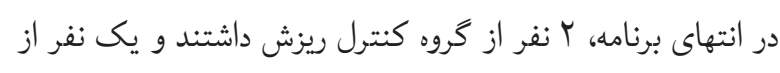
كروه آزمايش مايل به همكارى نشدند.

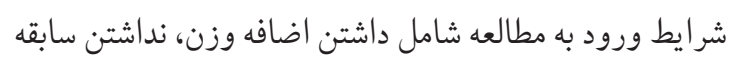
بيمارى از جمله ديابت، فشار خون و مشكلات حركتى، نداشتن

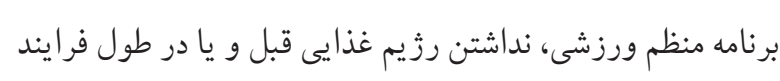

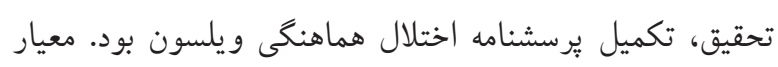
حذف آزمودنىها شامل حاضر نشدن در جلسات تمرينى بيش از بـاز ه جلسه و يا همكارى نكردن در طول جلسات بود د.

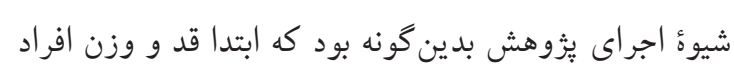

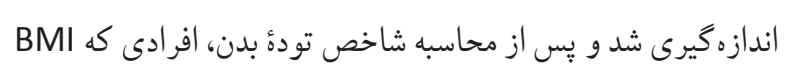

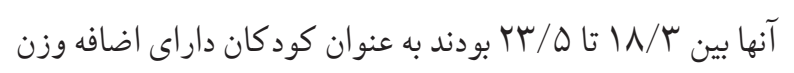

همان طور كه ملاحظه شد مطالعات، اثر فعاليت بدنى رادر تغيير

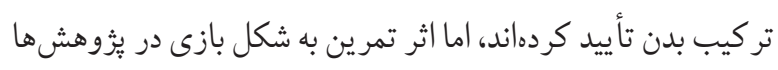

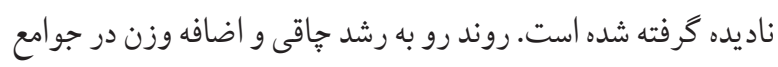

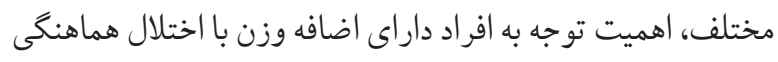

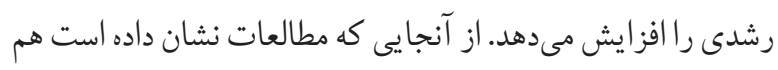

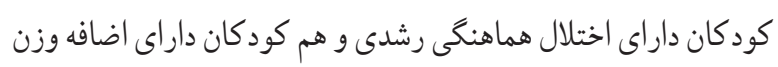

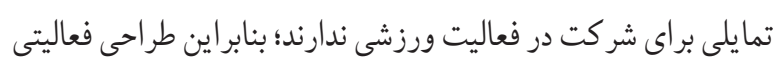

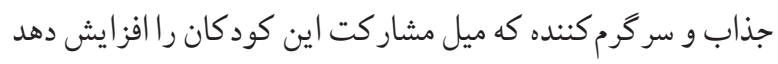

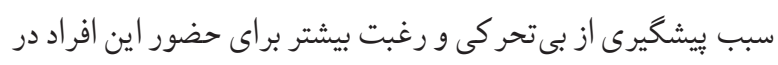
برنامههاى ورزشى مىشود. يكى از اشكال فعاليت بدنى بازى است.

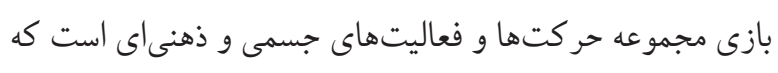

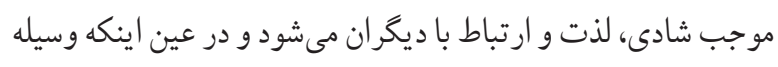

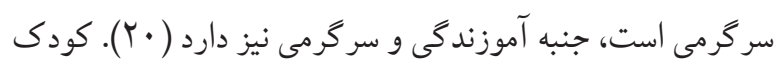

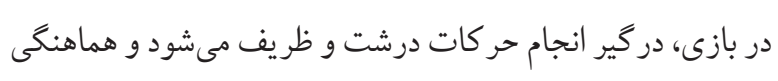

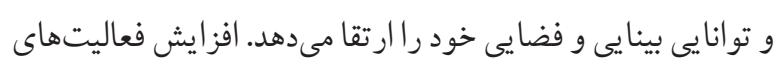

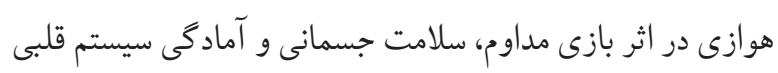

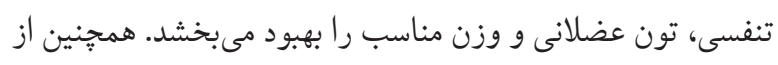

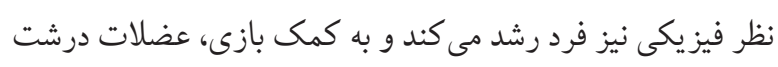

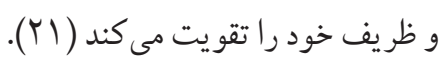

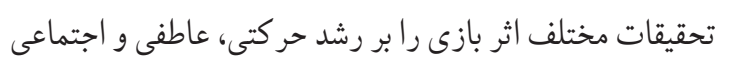

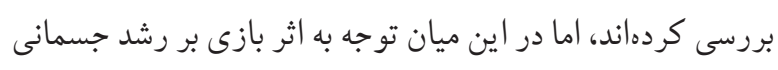
و تر كيب بدن و طراحى محيطى شاد براى فعاليت بدنى كود كان

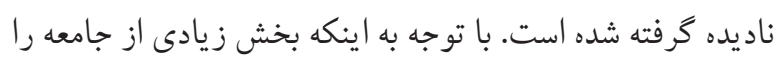

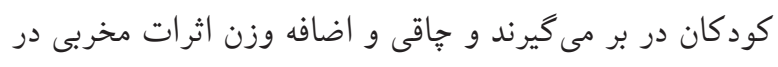

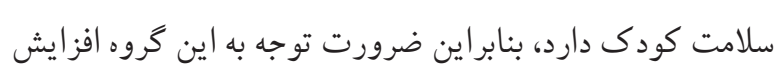

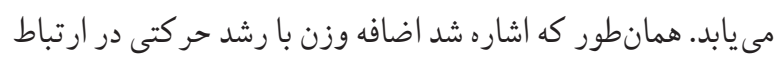

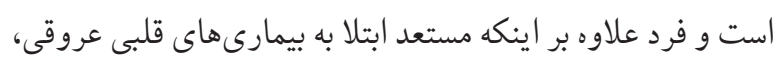

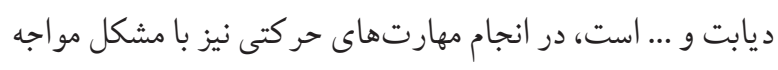
مىشود. بنابر اين هدف از مطالعه حاضر بررسى اين موضوع است

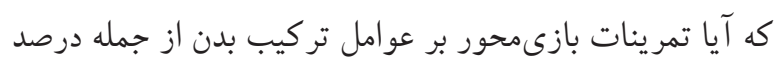
جربى، شاخص تودهُ بدن و وزن تاثير دارد يا خير. 
T-MABC Tمون

به منظور ارزيابى مهارتهاى حركتى كودكان از مجموعه آزمون T-MABC

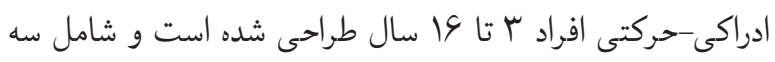
عامل جالاكى دست، دو آزمون مهارتهاى توبيى و سه آزمون تعادل

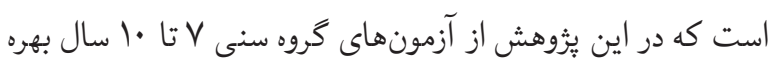

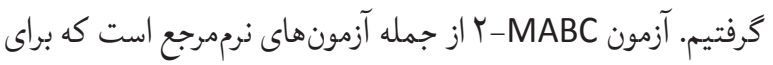
شناسايى اختلال هماهنكى در كودكان و نوجوانان استفاده ميىشود.

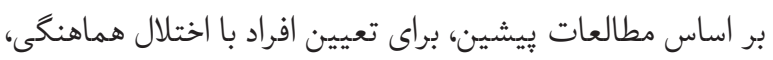

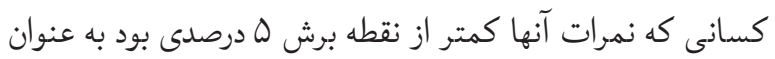
افراد داراى اختلال هماهنكى شناسايى شدند و كودكانى كه نمرات

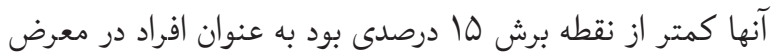

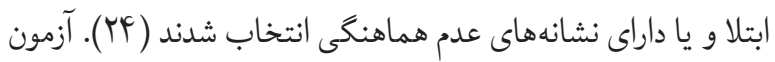
L-MABC

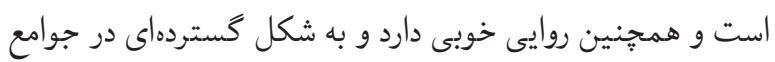

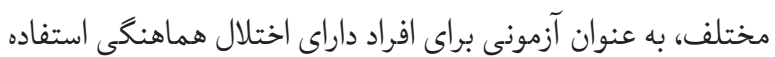

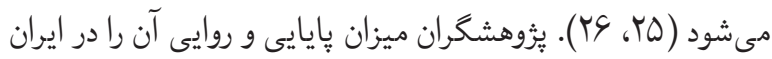

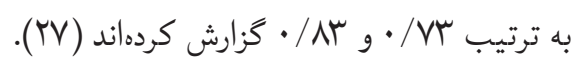
DCD-Qv به ترتيب وسنامه اين برسشنامه براى غربال اوليه افراد با اختلال هماهنكى استفاده

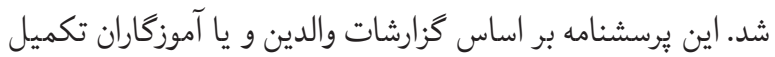

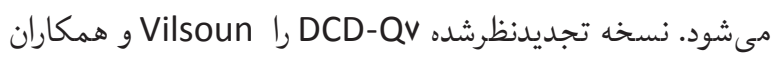

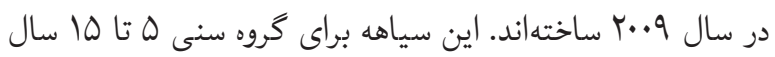

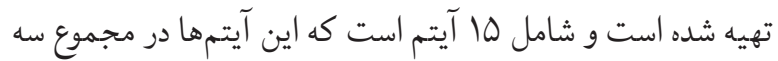
عامل كنترل در حين حركت، حركات ظريف/ دستخط و هماهنكى

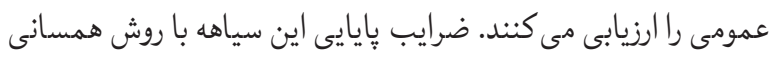

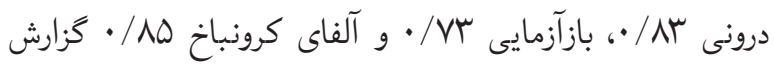
شده است (TN). در اين برسشنامه والدين در هر سؤال بايد درجه

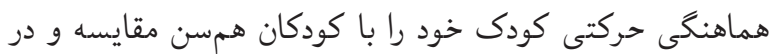
مقياس ليكرت ها ارزشى نمرهدهى كنند.
شناسايى شدند (YT). ستِ بِرسشنامه اختلال هماهنكى ويلسون

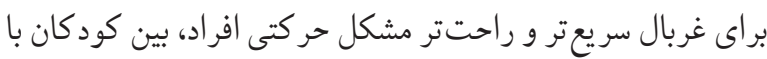

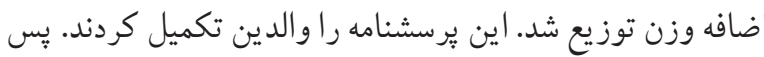
از جمع آورى يرسشناهها، هله كودى به عنوان افراد داراى اختلال

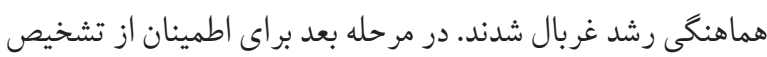

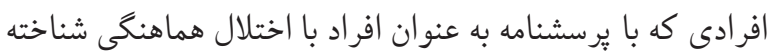

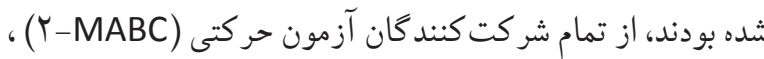

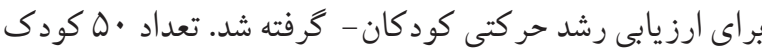

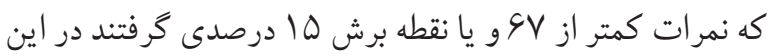

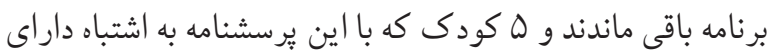
اختلال تشخيص داده شده بودند از فرايند تحقيق خارج شدند.

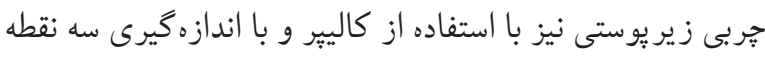
سه سر بازويى، تحت كتفى و ساق پِا طبق فرمول لومن محاسبه شد.

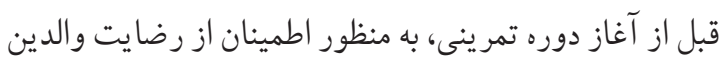

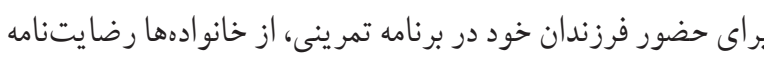

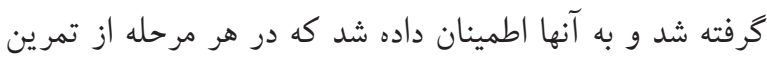
كودكان مجازند فرايند تمر ين را ترى كنند.

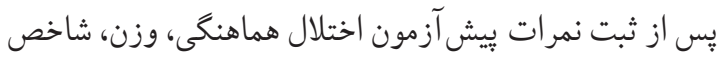

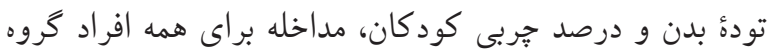

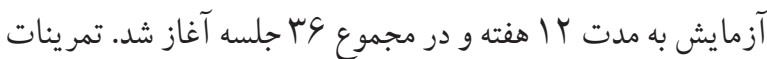

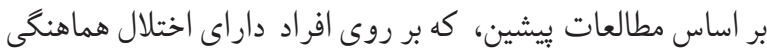

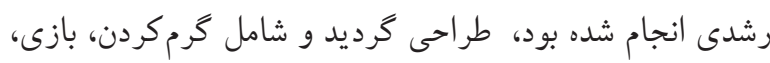
مهارتهاى توبى و تعادلى، مهارت هاى ظريف، و سردكردن بود.

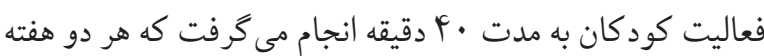

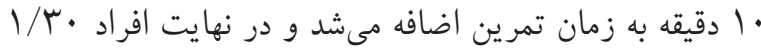

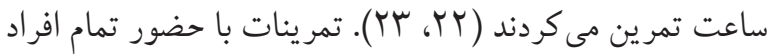

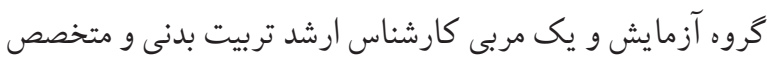

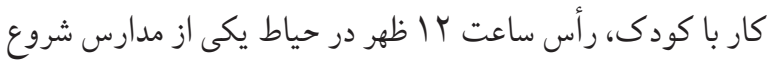
مىشد. گروه كنترل در اين مدت به فعاليتهاى روزمره خود مشغول

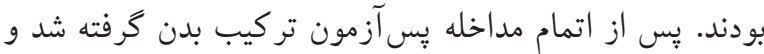

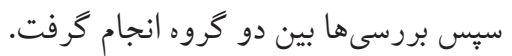


همان طور كه در جدول r مشخص است، نمرات يُ آزمون افراد

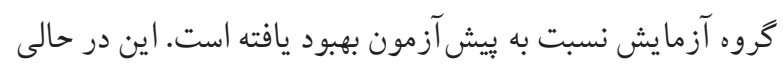

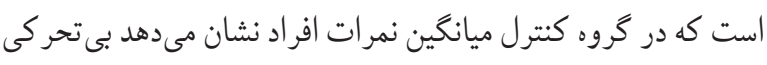
و نداشتن فعاليت بدنى موجب افزايش ميانگين وزن، شاخص توده بدن و درصد جربى مىشود.

جدول ا. مشخصات جمعيتشناختى شركت كند كًان

\begin{tabular}{|c|c|c|c|}
\hline قد & سن & تعداد & كروه \\
\hline $\mid \mu r / \cdot r$ & $\Lambda / \varsigma \wedge$ & rq & آزمايش \\
\hline $\mid r k / v$ & 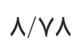 & 11 & كنترل \\
\hline
\end{tabular}

جدول ץ. شاخصهاى آمارى مربوط به عوامل تركيب بدن در كَروه

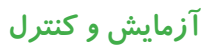

\begin{tabular}{|c|c|c|c|c|c|}
\hline كنترل & ميانغين & انحراف & ميانغين & كرون & متغير \\
\hline $\begin{array}{l}r / 11 \\
k / \mu 1\end{array}$ & $\begin{array}{l}r V / \cdot \Delta \\
r V / \Lambda \mu\end{array}$ & $\begin{array}{l}r / r r \\
r / V\end{array}$ & $\begin{array}{l}r s / 10 \\
r o / I V\end{array}$ & يِ پِ آز آزمون & وزن \\
\hline $\begin{array}{l}1 / \mu^{\prime} \\
1 / \mu^{\prime}\end{array}$ & $\begin{array}{l}r \cdot / 19 \\
r \cdot / 4 \wedge\end{array}$ & $\begin{array}{l}1 / 14 \\
1 / 4 r\end{array}$ & $\begin{array}{l}r \cdot / 1 F \\
19 / 0 .\end{array}$ & بيش پِّ آزمون & شاخص توده بدن " \\
\hline $\begin{array}{l}9 / .0 \\
0 / 99\end{array}$ & $\begin{array}{l}\mu l / q \Delta \\
\mu r / \mu .\end{array}$ & $\begin{array}{l}\Delta / \cdot \Delta \\
\Delta / V Q\end{array}$ & $\begin{array}{l}r \text { r } / Y r \\
r I / 19\end{array}$ & 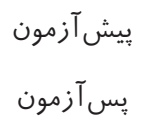 & درصد جربى : \\
\hline
\end{tabular}

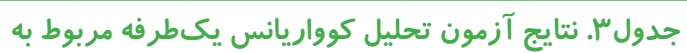
متغير هاى تركيب بدن بين گَروههاى تحقيق

\begin{tabular}{|c|c|c|c|c|c|c|}
\hline معنادارى & F مقدار F & مربعات مياتن & دآزادى & مربعات & واريان & متغيير \\
\hline$\cdot / \cdot 1$ & $4 / 9$ & $r r / l r$ & 1 & $1 \pi / r r$ & كروه & \\
\hline- & - & $1 / 9$. & fr & $\wedge r / \wedge 1$ & خطا & وزن \\
\hline- & - & - & iv & 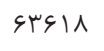 & كل & \\
\hline$\cdot 1 \cdots \Delta$ & N/S & ه/A & 1 & $\Delta / \wedge r$ & كروه & \\
\hline - & - & $\cdot / S V$ & fF & $r q / s r$ & خطا & شاخص تودهٔ بدن \\
\hline- & - & - & FV & $1 \wedge 9 Y 9$ & كل & \\
\hline$\cdot / \cdot r \Delta$ & $r / v r$ & $r \cdot / V$ & 1 & $r \cdot / V$ & 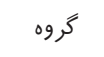 & \\
\hline- & - & f/r人 & fq & $19 \pi / .9$ & خطا & درصد جربى \\
\hline- & - & - & iv & Drrqu & كل & \\
\hline
\end{tabular}

قدسنج و ترازوى ديجيتالى

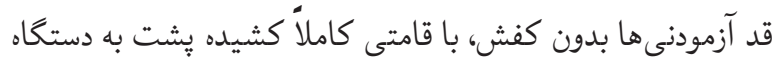

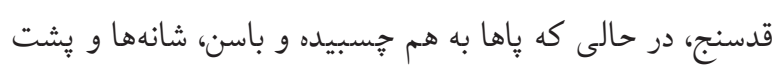

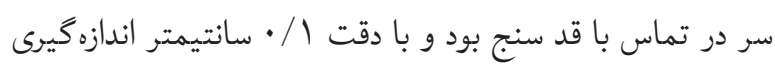

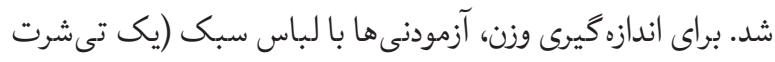
و شلوارى ورزشى) بدون كفش روى ترازو ايستادند و وزن آنها با باليا

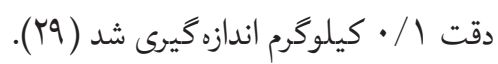
كاليبر براى سنجش درصد جربى بدن، ضخامت جربى زير يوستى در سه نقطه سه سر بازويى، تحت كتفى و ساق پا با استفاده از كاليبر اندازهيرى شد. تمام سنجش ها در سمت راست بدن انجام گرفت

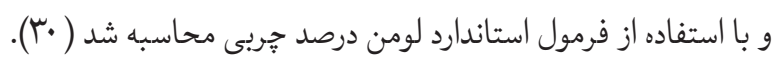

\section{FAT $=\sum 3$ Side $^{*} 0.610+5$}

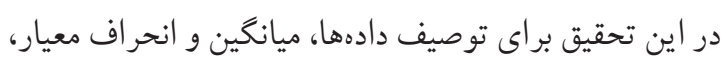
از آمار توصيفى و براى مقايسه دو گروه از آمار استنباطى بهره

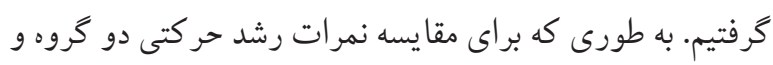

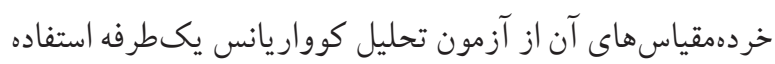

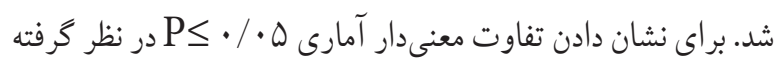
شد. براى محاسبات از نرمافزار آمارى SPSS نسخه إ استفاده شد.

يافته هـا

در اين تحقيق از آمار توصيفى براى ميانگين و انحراف معيار

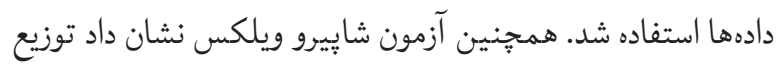
همه متغيرهاى موجود در تحقيق طبيعى است. بنابراين از آزمون

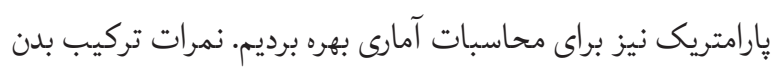

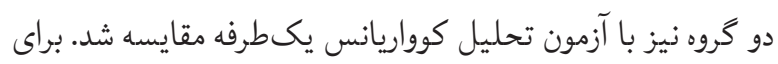

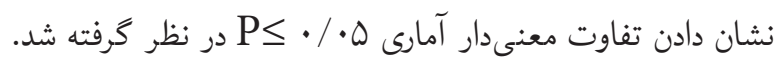
تمامى محاسبات با نرمافزار آمارى SPSS نسخه آب انجام كرفت. دادههاى مربوط به جو آزمودنى در كروه آزمايش با ميانكين

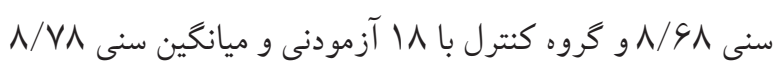
حاكى از تغييرات قابل توجه درگروه آزمايش است (جدول () ). 


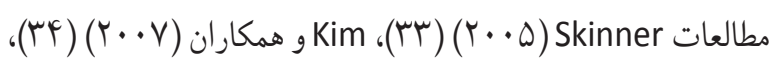

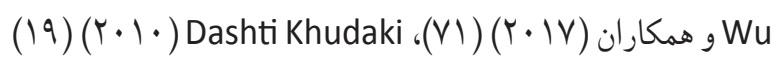

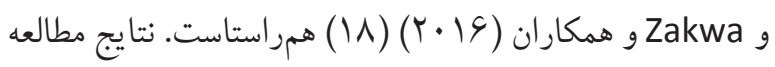

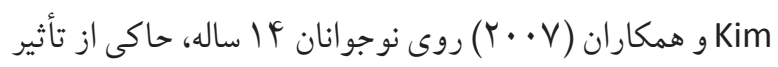

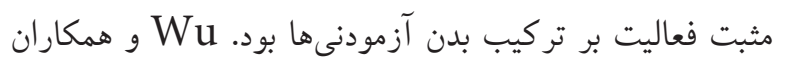

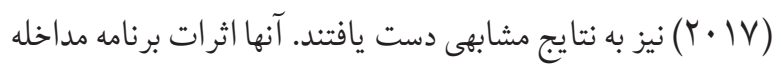
آموزش متقابل را بر روى تر كيب بدن، آمادكى قلبى تنفسى، تعادل

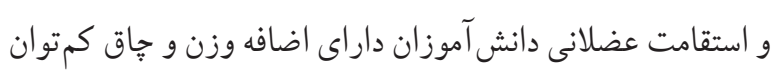
ذهنى بررسى كردند و نتايج بيانكر تغييرات معنادار تركيب بدن

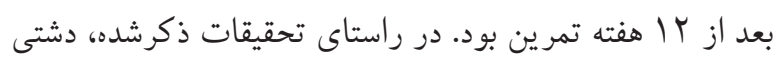

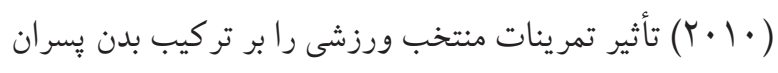

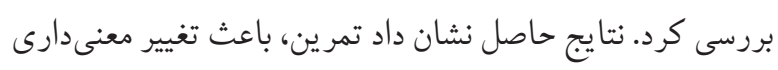

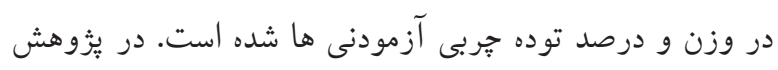

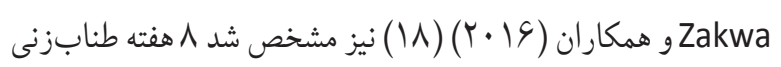

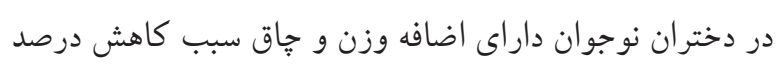
جربى، وزن و شاخص تودهُ بدن شده است. مىتوان كفت تمر ين

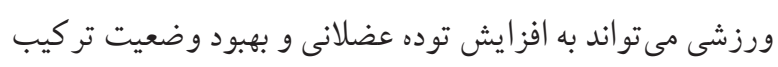

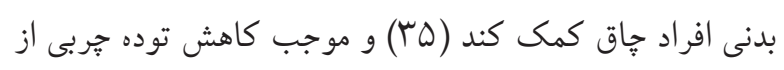

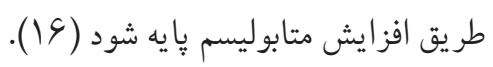

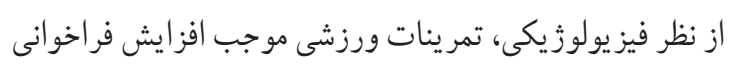

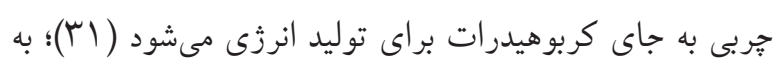

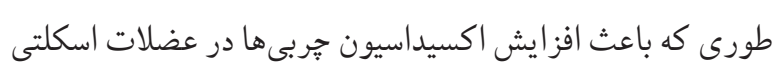

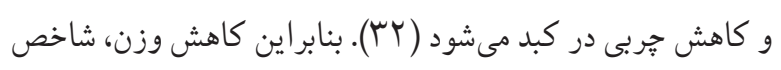

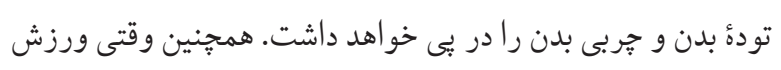

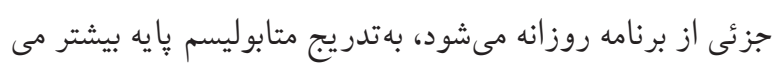

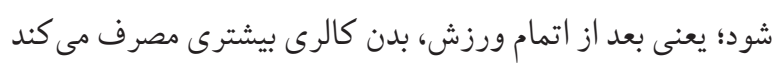

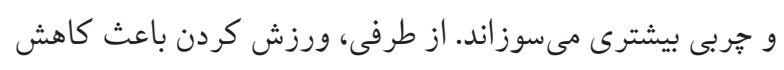

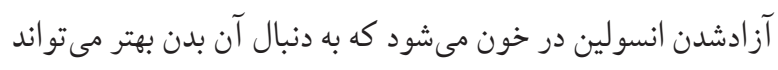

جربىهاى ذخيرهشده را آزاد كند ( آץ).

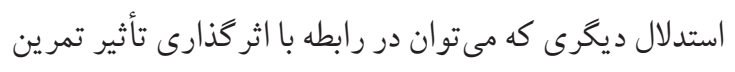
بر تركيب بدن ارائه داد، ترشح هورمونها در طول تمرين است.
نتايج نشان داد وزن بدن در گروه كنترل از هـ/ I د در بيش آزمون

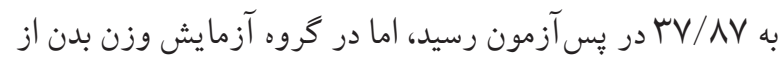

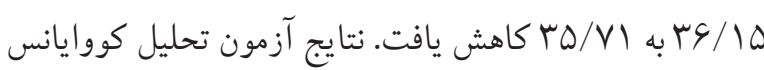

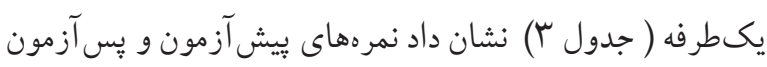

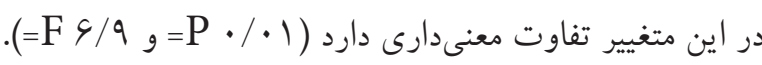

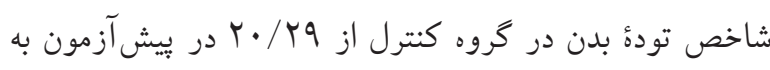

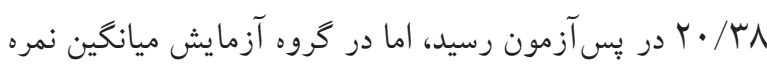

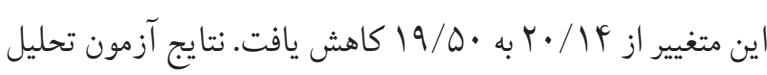

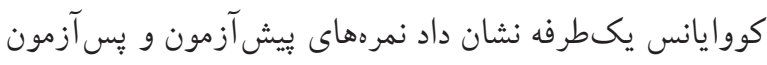

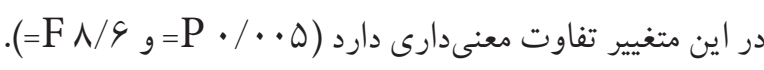

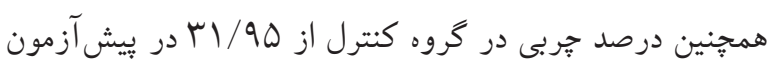
به بr/AV

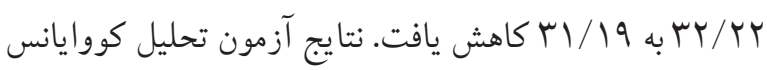
يكسطرفه نشان داد نمرههاى ييش آزمون و يس آزمون در اين متغيير

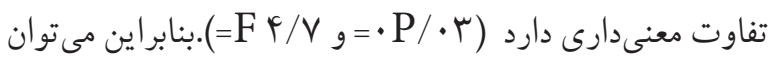

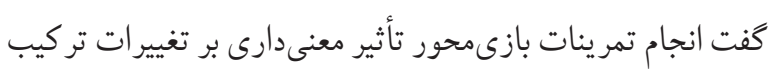
بدن داشته است. بحث هدف از يثوهش حاضر بررسى تاثير تمرينات بازىمحور بر تركيب

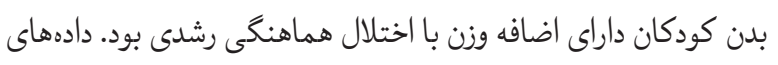

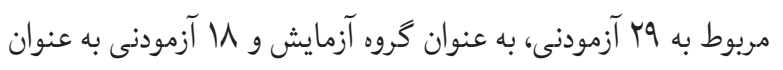

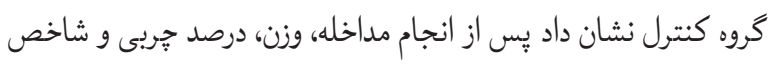

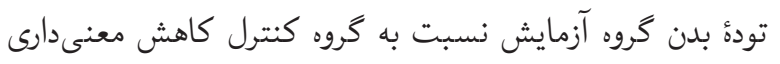

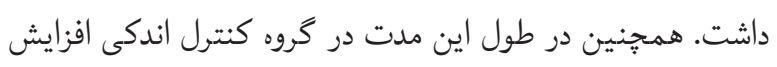
وزن، درصد جربى و شاخص تودة بدن ديده شده است. نتايج حاصل

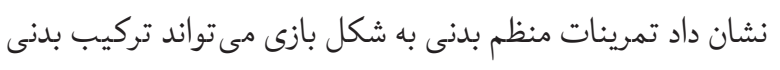

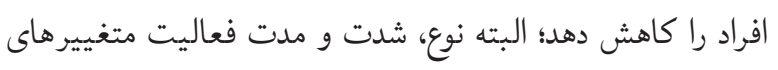

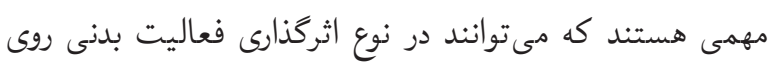

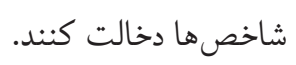
يافتهاى مطالعه حاضر درباره تأثير تمر ين بر تر كيب بدن با داني 
در اين يُوهش مىتواند به دليل هيجان، سر گرمى و مفرح بودن

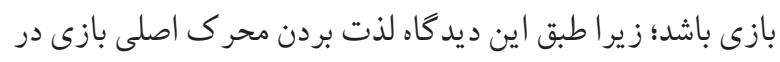

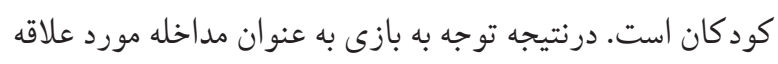

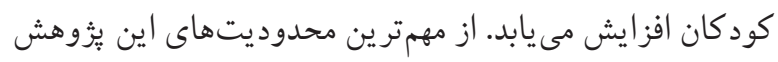

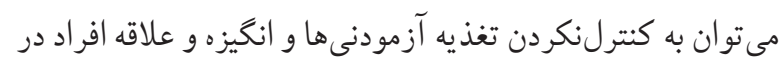
انجام تمرينات اشاره كرد كه خارج از كنترل محقق بود. بون بيشنهاد

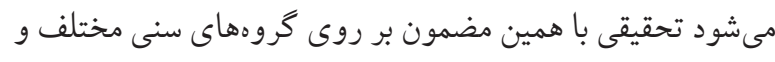

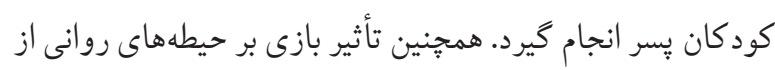

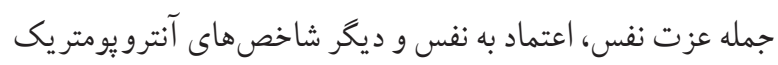
از جمله نسبت كمر به لخن بررسى شود. نتيجان كيرى

مرور مطالعات نشان مىدهد ورزش هوازى متوسط تا شديد بدون كاهش كالرى دريافتى، مى تواند موجب كاهش جربى شود. نتايج

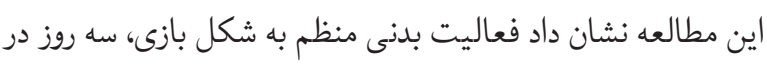

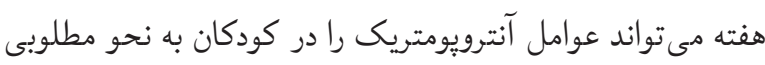
تغيير دهد. از نقاط قوت تحقيق حاضر اين بود كه در مطالعات ييشين تأثير تمرينات بازىمحور روى اين طيف از كودكان انجام

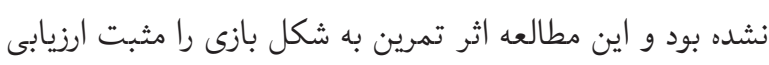

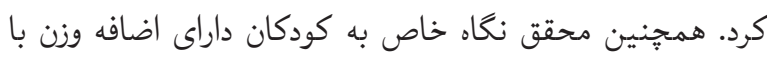

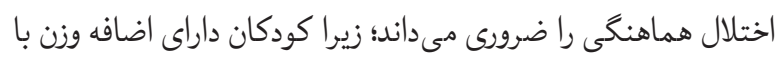

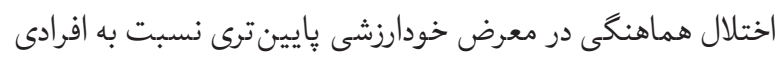

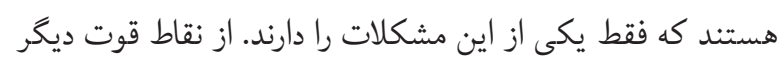
اين يزوهش، توجه به كودكان داراى اضافه وزن بود كه مشكلات

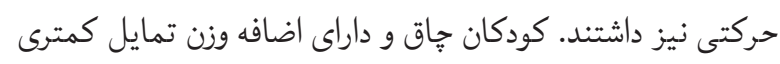
به انجام فعاليت حركتى دارند كه بيامد آن كمبود تجربه حركتى ني

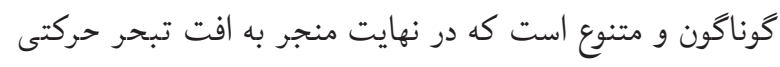

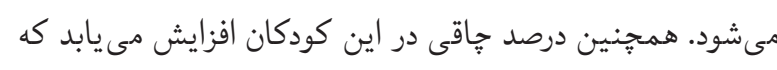
باعث بروز مشكلات قلبى و بيمارهايى از جمله ديابت و ... مى شود.

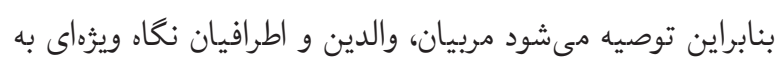

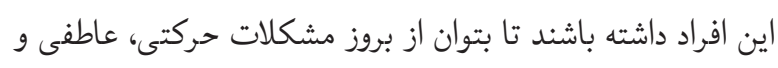
روانى در آينده جلوكيرى كرد.
هورمون ابىنفر ين كه در جر يان تمر ين ترشح مىشود، فعال كننده

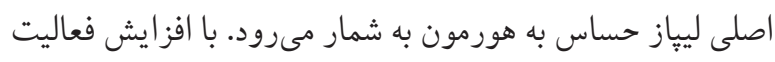

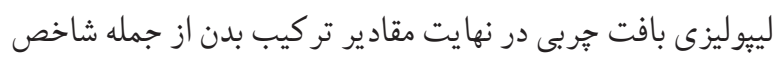

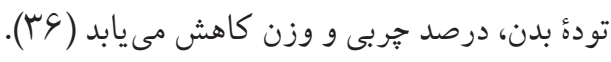

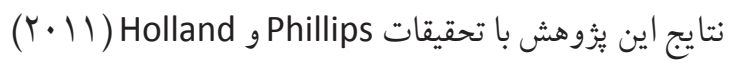

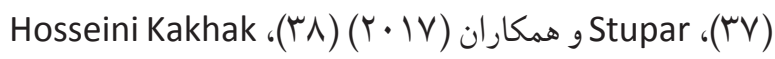

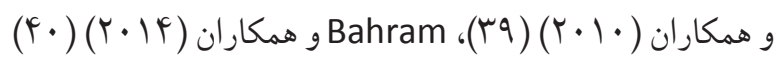

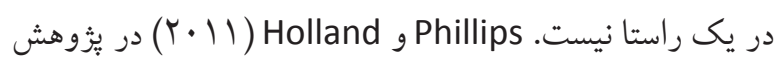

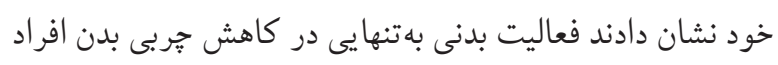

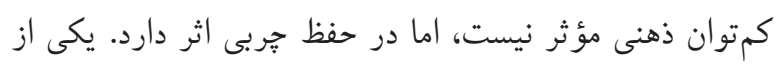

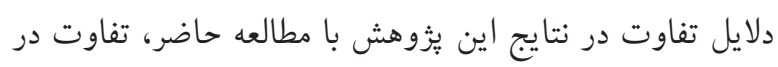

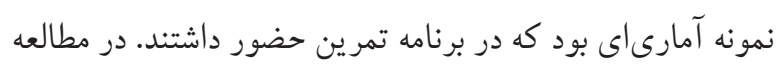
Hosseini Kakhak هو ازى تأثير معنىدارى روى درصد جربى آزمودنى ها نداشته است.

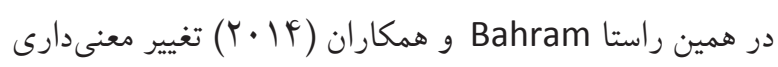

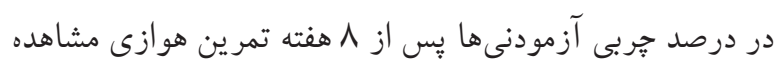

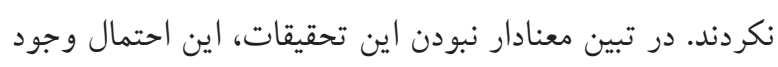

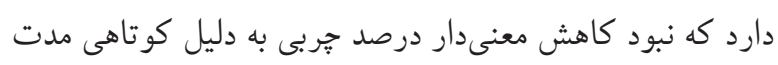

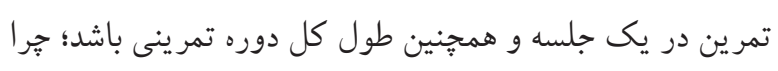

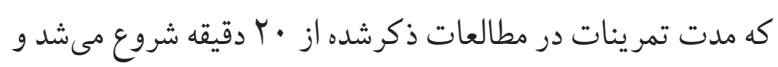

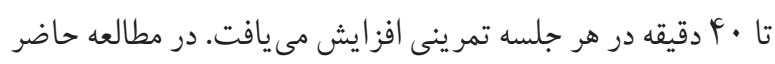

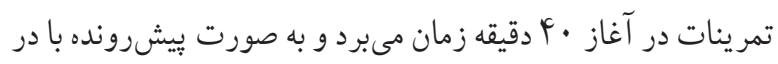

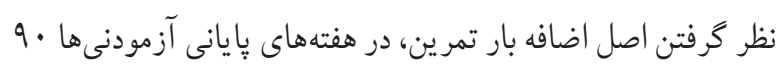

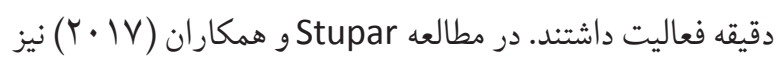
مشخص شد تمرينات ورزشى تأثير معنىدارى بر شاخص تودهُ بدن

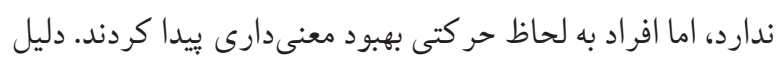
مهمى كه بتوان در اختلاف نتايج به آن اشاره كرد وزن آزمودنى هـا

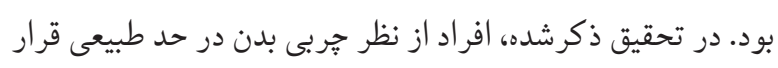
داشتند، در صورتى كه اكر افراد جاق يا داراى اضافه وزن انتخاب مىشدند، سرعت بيشترى در كاهش وزن ديده مى دـد.

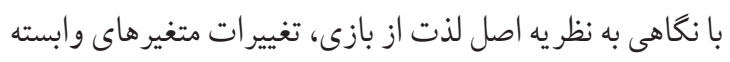




$$
\text { تحقيق همكارى داشتند، قدردانى مى شود. }
$$

سهم تمامى نويسندكان در اين مطالعه يكسان است و هيج گونه

$$
\text { تعارض در منافعى وجود ندارد. }
$$

\section{References}

1. Chinn S, Rona RJ. Prevalence and Trends in Overweight and Obesity in Three Cross Sectional Studies of British Children, 1974-94. BMJ. 2001; 322(7277):24-6.https:// www.bmj.com/content/322/7277/24.pdf+html https://doi.org/10.1136/bmj.322.7277.24 PMid:11141148 PMCid:PMC26603

2. Freedman DS, Sherry B. The Validity of BMI as an Indicator of Body Fatness and Risk Among Children. Pediatrics. 2009; 124(Supplement 1):S23-34S34.http://pediatrics.aappublications. org/content/124/Supplement_1/S23.short https://doi.org/10.1542/peds.2008-3586E PMid:19720664

3. Kelishadi R, Ardalan G, Gheiratmand R, Majdzadeh R, Hosseini $M$, Gouya MM, et al. Thinness, Overweight and Obesity in a National Sample of Iranian Children and Adolescents: CASPIAN Study. Child: Care, Health and Development. 2008; 34(1):44-54. https://onlinelibrary.wiley.com/doi/ abs/10.1111/j.1365-2214.2007.00744.x

4. Peyman N, Rezai-Rad M, Tehrani H, Gholian-Aval M, Vahedian-Shahroodi M, Heidarian Miri H. Digital Media-based Health Intervention on the promotion of Women's physical activity: a quasi-experimental study. BMC Public Health. 2018;18(1):134. https://doi.org/10.1186/s 12889-018-5025-5 PMid:29334970 PMCid:PMC5769504

5. Diagnostic AP. Statistical Manual of Mental Disorders: DSM5 (ed.) Washington, DC: American Psychiatric Association; 2013.

6. Cairney J, Hay J, Faught B, Mandigo J, Flouris A. Developmental Coordination Disorder, Self-Efficacy Toward Physical Activity, and Play: Does Gender Matter?. Adapted Physical Activity Quarterly. 2005; 22(1):67-82. http://journals. humankinetics.com/doi/abs/10.1123/apaq.22.1.67 https://doi.org/10.1123/apaq.22.1.67

7. Lingam R, Hunt L, Golding J, Jongmans $M$, Emond $A$. Prevalence of Developmental Coordination Disorder Using the DSM-IV at 7 Years of Age: A UK PopulationBased Study. Pediatrics. 2009; 123(4):e693-700. http://
اين يزوهش از رساله دكتراى تخصصى گرفته شده است كه در تاريخ

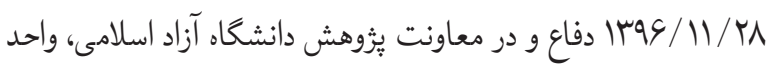

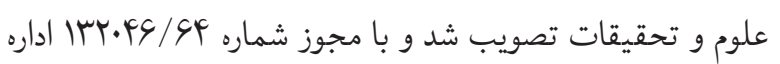

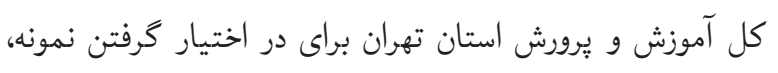

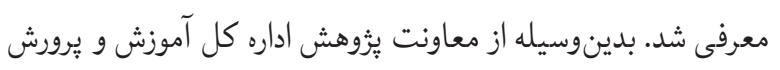

pediatrics.aappublications.org/content/123/4/e693.short https://doi.org/10.1542/peds.2008-1770 PMid:19336359

8. Missiuna C, Moll S, King G, Stewart D, Macdonald K. Life Experiences of Young Adults Who Have Coordination Difficulties. Canadian Journal of Occupational Therapy. 2008; 75(3):157-66. http://journals.sagepub. com

https://doi.org/10.1177/000841740807500307 PMid:18615927

9. Cairney J, Kwan MY, Hay JA, Faught BE. Developmental Coordination Disorder, Gender, and Body Weight: Examining the Impact of Participation in Active Play. Research in Developmental Disabilities. 2012; 33(5):1566-73. https://www.sciencedirect. com/science/article/pii/S0891422212000546 https://doi.org/10.1016/j.ridd.2012.02.026 PMid:22522216

10. Lloyd M, Reid G, Bouffard M. Self-Regulation of Sport Specific and Educational Problem-Solving Tasks by Boys With and Without DCD. Adapted Physical Activity Quarterly. 2006; 23(4):370-89.

https://doi.org/10.1123/apaq.23.4.370

11. Rivilis I, Hay J, Cairney J, Klentrou P, Liu J, Faught BE. Physical Activity and Fitness in Children With Developmental Coordination Disorder: A Systematic Review. Research in Developmental Disabilities. 2011; 32(3):894-910. https://www.sciencedirect. com/science/article/pii/S0891422211000187 https://doi.org/10.1016/j.ridd.2011.01.017 PMid:21310588

12. Wagner MO, Kastner J, Petermann F, Jekauc D, Worth A, Bös K. The Impact of Obesity on Developmental Coordination Disorder in Adolescence. Research in Developmental Disabilities. 2011; 32(5):1970. https://www.sciencedirect. com/science/article/pii/s0891422211001521 https://doi.org/10.1016/j.ridd.2011.04.004 PMid:21596520 
13. Sharif, P. Determining the Relationship Between Correlation Between Physical Self-Concept and Selection of Physical Fitness Factors and Physical Activity Level of Female Students of Isfahan University. Master's Thesis. Tarbiat Moalem University. 2002.

14. Shahriyari, M. Teen Psychology Psychology (Developmental View). Tehran: Science Publishing; 2005.

15. Rezaei Shirazi, M. The Effect of 12 Weeks of Severe Intolerant Training on Plasma Levels of Leptin, Adiponectin and Insulin Resistance Index in Obese Men with Fatty Liver Disease. Journal of Metabolism and Sports. 2015; 5(1):23-24. http:// jme.guilan.ac.ir/article_1692.html

16. Pratley R, Nicklas B, Rubin M, Miller J, Smith A, Smith M, et al. Strength Training Increases Resting Metabolic Rate and Norepinephrine Levels in Healthy 50-to 65-yr-Old Men. Journal of Applied Physiology. 1994; 76(1):133-7. https:// www.physiology.org/doi/abs/10.1152/jappl.1994.76.1.133 https://doi.org/10.1152/jappl.1994.76.1.133 PMid:8175496

17. Wu WL, Yang YF, Chu IH, Hsu HT, Tsai FH, Liang JM. Effectiveness of a Cross-Circuit Exercise Training Program in Improving the Fitness of Overweight or Obese Adolescents With Intellectual Disability Enrolled in Special Education Schools. Research in Developmental Disabilities. 2017; 60:83-95. https://www.sciencedirect. com/science/article/pii/S0891422216302487 https://doi.org/10.1016/j.ridd.2016.11.005 PMid:27914305

18. Zakwa E, Dodman K, Isa Zadeh, R. The Effect of Eight Weeks of Cord Training on Some of the Immune System Indicators of Overweight and Obese Teenagers. Journal of Applied Research of Sport Sciences Without Borders. 2016; 1(3):73-92.

19. Dashti Khudaki MH. The Effect of the Selected Exercise Program on Body Composition and Heart Rate of 11-13 Year Old Male Students. Zahedan Journal of Research in Medical Sciences. 2010; 13(6):40-43. http://zjrms.ir/article1-1494-en.pdf

20. Jafari A. The Impact of Traditional Educational Games on the Academic Achievement of Elementary School Students in Tehran. PhD Dissertation. Tajik National University. 2011.

21. Samadi SA. Therapeutic Games (Theories, Research and Intervention Methods). Tehran: Dange Publishing. Third edition. 2014.
22.ColeTJ,BellizziMC,FlegalKM, DietzWH.EstablishingaStandard

Definition for Child Overweight and Obesity Worldwide: International Survey. BMJ. 2000; 320(7244):1240. https:// www.bmj.com/content/320/7244/1240.pdf+html https://doi.org/10.1136/bmj.320.7244.1240 PMid:10797032 PMCid:PMC27365

23. Morton C. The Effect of a Group Motor Skills Programme on the Participation and Movement Ability of Children With Developmental Coordination Disorder. Master's Thesis. University College Dublin. 2015. http://irserver.ucd.ie/ handle/10197/6811

24. Moradi H, Khodashenas E, Sohrabismeaneh Teimouri M, Shayan Noushabadi A. Effect of Spark Motion Program on Sensory-Motor Function in Children with Disorders Growth Coordination [in Persian]. Journal of Kashan University of Medical Sciences, December, 2015; 19(5):391-398. http:// feyz.kaums.ac.ir/article-1-2860-fa.pdf

25. Henderson SE, Sugden DA, Barnett AL. Movement Assessment Battery for Children-2: MABC-2. London: Pearson Assessment; 2007. https://doi.org/10.1037/t55281-000

26. Schulz J, Henderson SE, Sugden DA, Barnett AL. Structural Validity of the Movement ABC-2 Test: Factor Structure Comparisons Across Three Age Groups. Research in Developmental Disabilities. 2011; 32(4):1361-9. https://www.sciencedirect. com/science/article/pii/S0891422211000333 https://doi.org/10.1016/j.ridd.2011.01.032 PMid:21330102

27. Samadi M, Nazemzadegan GH, Hadian Fard H. Determining the Reliability, Validity and Standardization of the Total Test of Motor Vehicle Evaluation in Second and Third Year in Shiraz 7 and 8 Year Old Children. Master's Thesis. Shiraz University. 2015.

28. Wilson BN, Crawford SG, Green D, Roberts G, Aylott A, Kaplan BJ. Psychometric Properties of the Revised Developmental Coordination Disorder Questionnaire. Physical \& Occupational Therapy in Pediatrics. 2009; 29(2):182-202. https://www.tandfonline. com/doi/abs/10.1080/01942630902784761 https://doi.org/10.1080/01942630902784761 PMid:19401931

29. Gillum RF. Distribution of Waist-to-Hip Ratio, Other Indices of Body Fat Distribution and Obesity and Associations 
With HDL Cholesterol in Children and Young Adults Aged 4-19 Years: The Third National Health and Nutrition Examination Survey. International Journal of Obesity. 1999; 23(6):556. https://www.nature.com/articles/0800866 https://doi.org/10.1038/sj.ijo.0800866 PMid:10411227

30. Lohman TG, Roche AF. Anthropometric Standardization Reference Manual. Martorell R, editor. Champaign: Human Kinetics Books; 1988. https://gte7i8tsq01.storage. googleapis.com/MDg3MzlyMTIxNA==01.pdf

31. Khajuvi M, Beezeh N, Moazami M. The Effect of Twelve Weeks of Aerobic Training on Serum Lipid Profiles, Aerobic Power and Body Composition of Non-Athletic Mentally Retarded Girls. Shahrekord Medical Journal. 2012; 16(1):5664. http://journal.skums.ac.ir/article-1-1147-fa.pdf

32. Moody H, Ghiyasi F, Afshar M, Akbari A. Harati H, Moody $M$, Sheikh Zadeh A. The Effect of Pleomometric and Aerobic Exercises on Chest Expandability and Pulmonary Volume in High School Students. Shahrekord Medical Journal. 2008; 11(2):30-38. https://journal.skums.ac.ir/browse.php?a_ code=A-10-3-275\&slc_lang=fa\&sid=1\&sw=\%D8\%B9\%D8\% B6\%D9\%84\%D8\%A7\%D9\%86\%DB\%8C

33. Skinner JS. Physiological Response of Men to I, 3 and 5 Day Per Week Training Programs. Journal of Research Sport. 2005; 57(2):62-75.

34. Kim ES, Im JA, Kim KC, Park JH, Suh SH, Kang ES, et al. Improved Insulin Sensitivity and Adiponectin Level After Exercise Training in Obese Korean Youth. Obesity. 2007; 15(12):3023-30. https://onlinelibrary. wiley.com/doi/abs/10.1038/oby.2007.360 https://doi.org/10.1038/oby.2007.360 PMid:18198311

35. Rezaei Shirazi R. The Effect of 12 Weeks of Severe Intolerant Training on Plasma Levels of Leptin, Adiponectin and Insulin Resistance Index in Obese Men With Fatty Liver Disease. Journal of Metabolism and Sports. 2014; 5(1):23-24. http:// jme.guilan.ac.ir/article_1692.html

36. Nicklas BJ, Hsu FC, Brinkley TJ, Church T, Goodpaster
BH, Kritchevsky SB, Pahor M. Exercise Training and Plasma C-Reactive Protein and Interleukin-6 in Elderly People. Journal of the American Geriatrics Society. 2008; 56(11):2045-52. https://onlinelibrary.wiley. com/doi/abs/10.1111/j.1532-5415.2008.01994.x https://doi.org/10.1111/j.1532-5415.2008.01994.x PMid:19016938 PMCid:PMC2683336

37. Phillips AC, Holland AJ. Assessment of Objectively Measured Physical Activity Levels in Individuals With Intellectual Disabilities With and Without Down's Syndrome. PLoS One. 2011; 6(12):e28618. http://journals.plos.org/ plosone/article?id=10.1371/journal . pone .0028618 https://doi.org/10.1371/journal.pone.0028618 PMid:22205957 PMCid:PMC3244403

38. Stupar D, Popovic B, Romanov R, Jankovic M, Jezdimirovic T, Medjedovic B. The Effects of Specific Exercise Program on Anthropometric Characteristics and Motor Abilities of Preschool Children. International Journal of Morphology. 2017; 35(3). https://www.researchgate.net/profile/Dusan_ Stupar2/publication/320120189_The_Effects_of_Specific Exercise_Program_on_Anthropometric_Characteristics_ and_Motor_Abilities_of_Preschool_Children/ links/59f83598458515547c24ebb4/The-Effects-of-SpecificExercise-Program-on-Anthropometric-Characteristicsand-Motor-Abilities-of-Preschool-Children.pdf https://doi.org/10.4067/S0717-95022017000300038

39. Hosseini Kakhak SAR, Amiri Parsa T, Azarniveh M, Hamedinia, MR. Effect of Aerobic Training and Subsequent Infertility on Kidney Function Indices in Obese Girls. Journal of Sport Sciences. 2010; 14(11):89-102. https://jsb.ut.ac.ir/ article_24995.html

40. Bahram MI, Pourvagar MJ, Mojtahedi H, Movahedi, AR. Effect of 8 Weeks Aerobic Training on Some Indicators of Cardiovascular Endurance and Physical Fitness of High School Boy Students in Kashan. Journal of Applied Life Sciences in Sport. 2014; 2(4):90-98. http://jpsbs.birjand. ac.ir/article_25.html 